\section{it-sa 2017}

Vom 10. bis 12. Oktober findet die it-sa erstmals in zwei Hallen des Messezentrums Nürnberg statt. Europas ausstellerreichste IT-Sicherheitsfachmesse wächst weiter, um der hohen Nachfrage in- und ausländischer IT-Sicherheitsanbieter nachzukommen, wurde die Messe in diesem Jahr vergrößert.

Die Erpressungssoftware „Wanna Cry“ hat innerhalb kürzester Zeit weltweit hunderttausende Computer lahmgelegt. Darunter solche der Deutschen Bahn und von Krankenhäusern. Die Attacke zeigt erneut, wie verwundbar moderne IT-Infrastrukturen sind. Wie sich Unternehmen und Organisationen vor vielfältigen Sicherheitsbedrohungen schützen können, zeigt die Fachmesse it-sa. Mit ihrer klaren Fokussierung auf das Thema IT-Security hat sie sich in den vergangenen Jahren eine herausragende Position in der europäischen Messelandschaft erarbeitet. Mit zuletzt 489 Ausstellern erreichte sie 2016 die Kapazitätsgrenzen der Halle 12, in der sie seit der Erstveranstaltung 2011 stattfand. Zur it-sa 2017 wechselt die Veranstaltung deshalb in die Hallen 9 und 10. Bereits heute liegt die gebuchte Ausstellungsfläche ein Viertel über der der Vorveranstaltung.

\section{Positive Resonanz der Aussteller}

„Die positive Resonanz der bestehenden Aussteller, zahlreiche Neuanmeldungen und eine Vielzahl an Standvergrößerungen versprechen eine nochmals größere it-sa. Mit dem Umzug schaffen wir den für das weitere Wachstum der it-sa benötigten Raum“, so Frank Venjakob, Executive Director

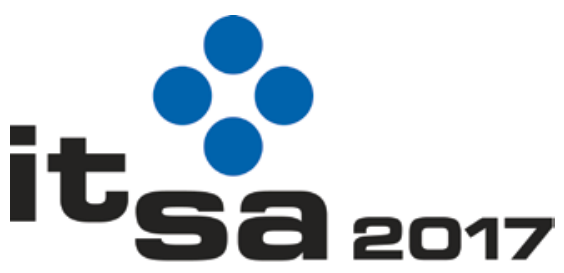

Die IT-Security Messe und Kongress The IT Security Expo and Congress

it-sa, NürnbergMesse. Besucher erreichen die Fachmesse jetzt direkt über den Eingang Mitte des Messezentrums Nürnberg. Das begleitende Kongressprogramm Congress@it-sa findet wie gewohnt in unmittelbarer Nähe der Messe statt und ist ebenfalls über den Eingang Mitte zugänglich.

\section{Umfassender Marktüberblick als Erfolgsrezept} Unverändert bleibt das erfolgreiche Messekonzept: Bis hin zum physischen Schutz für Rechenzentren deckt die it-sa das gesamte Spektrum aktueller IT-Security-Lösungen aus den Bereichen Hard- und Software, Forschung und Beratungsdienstleistungen sowie Services ab. Ausstellerbeiträge in den offenen Foren ergänzen das Informationsangebot um praxisnahe Wissensvermittlung, Branchen-Know-how und Diskussionen zu aktuellen IT-Sicherheitsfragen. In einer aktuellen Mitgliederbefragung des Bundesverbands IT-Sicherheit TeleTrusT zu Präferenzen und Teilnahmeverhalten bei ITSicherheitsmessen erfuhr die it-sa den größten Zuspruch unter allen relevanten Veranstaltungen in Europa.

Weitere Informationen unter anderem zu Preisen und Öffnungszeiten finden Sie unter: www.it-sa.de

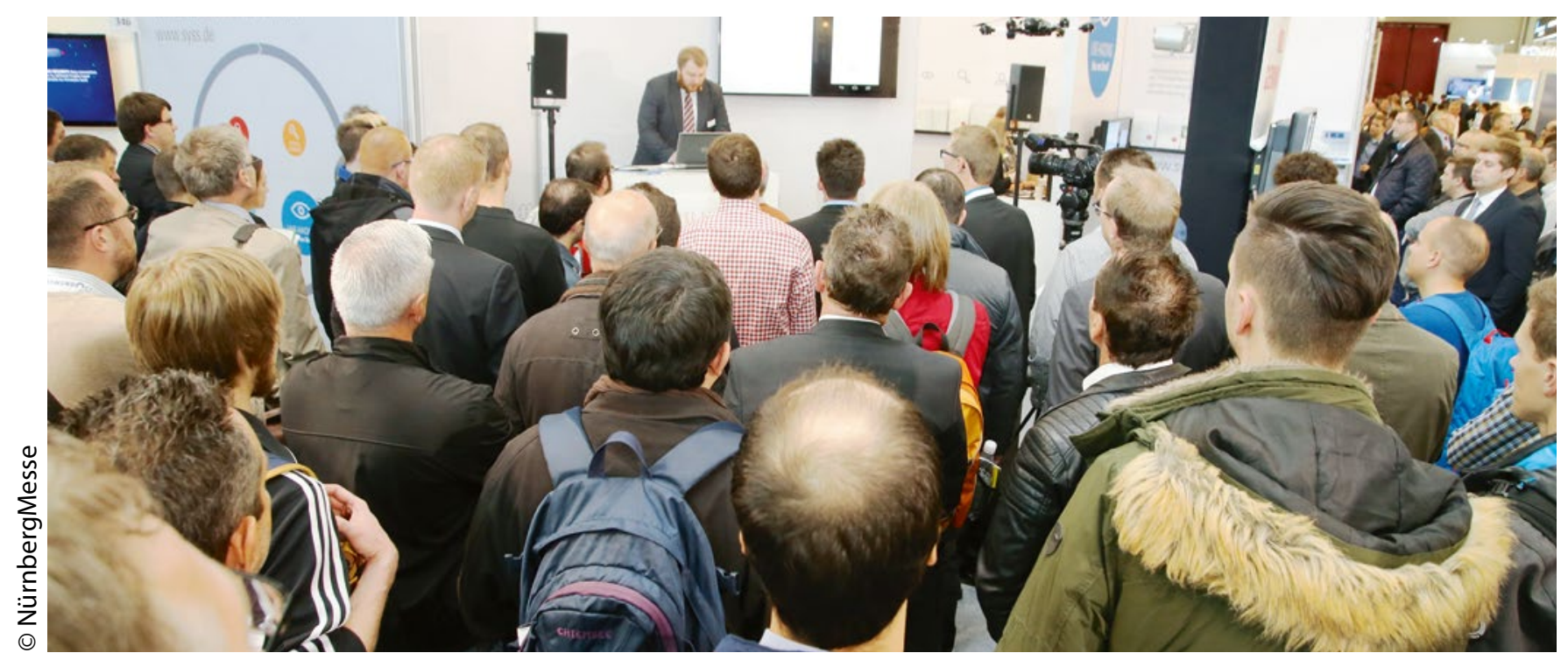

Auf großes Interesse stoßen die Fachvorträge während der Messe. 